\title{
Supplementation of Vitamin D in the Postdelivery Period of Women with Previous Gestational Diabetes Mellitus: Systematic Review and Meta-Analysis of Randomized Trials
}

\section{Suplementacão da vitamina $D$ no período pós-parto de mulheres com diabetes mellitus gestacional anterior: revisão sistemática de ensaios clínicos randomizados}

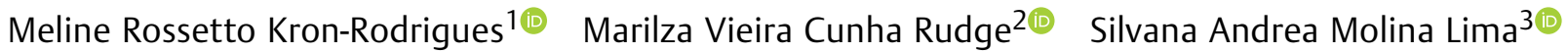 \\ ${ }^{1}$ Universidade Guarulhos, Programa de Pós-Graduação em \\ Enfermagem (Stricto Sensu), Guarulhos, SP, Brazil \\ 2 Departamento de Ginecologia e Obstetrícia, Universidade Estadual \\ Paulista "Júlio de Mesquita Filho," Botucatu, SP, Brazil \\ ${ }^{3}$ Departamento de Enfermagem, Universidade Estadual Paulista \\ "Júlio de Mesquita Filho", Botucatu, SP, Brazil \\ Address for correspondence Meline Rossetto Kron-Rodrigues, Dra., \\ Praça Teresa Cristina, 229, Guarulhos, SP, 07023-070, Brazil \\ (e-mail: me_kron@hotmail.com).
}

Rev Bras Ginecol Obstet 2021;43(9):699-709.

\begin{abstract}
Keywords

- gestational diabetes

- vitamin D

- meta-analysis

- postpartum period

- systematic review

Objective To evaluate the effects of vitamin D supplementation in the postpartum period of women with previous gestational diabetes mellitus (GDM).

Methods Randomized clinical trials of pregnant women with GDM of any chronological, gestational age and parity, with no history of previous disease who received vitamin D supplementation in the prenatal and/or postpartum period and were evaluated in the postpartum period were included. The PubMed, EMBASE, Cochrane, and LILACS databases were consulted until July 2019. Serum vitamin D concentration (25hydroxyvitamin $\mathrm{D}$ in $\mathrm{nmol} / \mathrm{L}$ ), fasting blood glucose, glycated hemoglobin, serum calcium concentration, homeostatic model assessment of insulin resistance (HOMAIR), quantitative insulin sensitivity check index (QUICKI), parathyroid hormone (PTH) and body mass index (BMI) were evaluated. Similar results in at least two trials were plotted using the RevMan 5; Cochrane Collaboration, Oxford, Reino Unido. The quality of the evidence was generated according to the classification, development, and evaluation of the classification of the recommendations.

Results Four studies were included in the present review (200 women). The findings indicate that there is no difference in the postpartum period in women diagnosed with previous GDM who received vitamin D supplementation in the prenatal and/or in the postpartum period, showing only that there was a significant increase in the concentration of vitamin D (relative risk [RR]: 1.85; 95\% confidence interval [Cl]: 1.02-2.68).
\end{abstract}

received

January 9, 2021

accepted

June 17, 2021
DOI https://doi.org/ 10.1055/s-0041-1734000. ISSN 0100-7203.

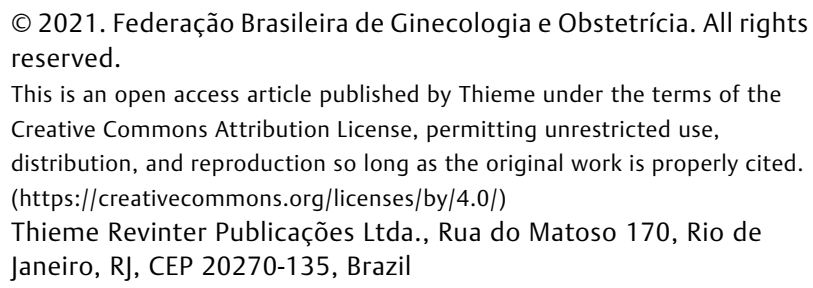

(c) 2021. Federação Brasileira de Ginecologia e Obstetrícia. All rights reserved.

This is an open access article published by Thieme under the terms of the Creative Commons Attribution License, permitting unrestricted use, distribution, and reproduction so long as the original work is properly cited. (https://creativecommons.org/licenses/by/4.0/)

Thieme Revinter Publicações Ltda., Rua do Matoso 170, Rio de Janeiro, RJ, CEP 20270-135, Brazil 


\section{Resumo}

\author{
Palavras-chave \\ - diabetes gestacional \\ - vitamina D \\ - metanálise \\ - período pós-parto \\ - revisão sistemática
}

\begin{abstract}
Conclusion This increase in the concentration of vitamin D should be interpreted with caution, since the assessment of the quality of the evidence was very low. For the other analyzed outcomes, there was no significance between the intervention and control groups, and the outcomes, when analyzed in their strength of evidence, were considered very low and low in their evaluation.
\end{abstract}

Objetivo Avaliar os efeitos da suplementação de vitamina $D$ no pós-parto de mulheres com diabetes mellitus gestacional (DGM) anterior.

Métodos Foram incluídos ensaios clínicos randomizados com gestantes com GDM de qualquer idade cronológica, gestacional e paridade, sem história de doença prévia, que receberam suplementação de vitamina $D$ no pré-natal e/ou no pós-parto e foram avaliadas no pós-parto. As bases de dados consultadas foram PubMed, EMBASE, Cochrane e LILACS, até julho de 2019. Foram avaliados concentração sérica da vitamina D (25-hidroxivitamina D em nmol/L), glicemia de jejum, hemoglobina glicada, concentração sérica de cálcio, modelo de avaliação da homeostase de resistência à insulina (HOMA-IR, na sigla em inglês), índice qualitativo de verificação da sensibilidade à insulina (QUICKI, na sigla em inglês), hormônio da paratireoide (PTH) e índice de massa corpórea (IMC). Resultados semelhantes em pelo menos dois ensaios foram plotados no software RevMan 5; Cochrane Collaboration, Oxford, Reino Unido. A qualidade das evidências foi gerada de acordo com a classificação, o desenvolvimento e a avaliação da classificação das recomendações.

Resultados Quatro estudos foram incluídos na presente revisão (200 mulheres). Os achados indicam que não há diferença no período pós-parto em mulheres com diagnóstico prévio de DMG que receberam suplementação de vitamina $D$ no período pré-natal e/ou pós-parto, mostrando apenas que houve um aumento significativo na concentração de vitamina $D$ (risco relativo [RR]: 1,85; IC [intervalo de confiança] 95\%: 1,02-2,68).

Conclusão Este aumento na concentração de vitamina $D$ deve ser interpretado com cautela, uma vez que a avaliação da qualidade das evidências foi muito baixa. Para os demais desfechos analisados, não houve significância entre os grupos intervenção e controle, e os desfechos, quando analisados em sua força da evidência, foram considerados muito baixa e baixa em sua avaliação.

PROSPERO CRD42018110729

\section{Introduction}

Diabetes mellitus (DM) is characterized as a heterogeneous group of metabolic disorders that have hyperglycemia in common, resulting from defects in the action and/or in the secretion of insulin. ${ }^{1}$ Diabetes mellitus can be classified into four general categories: type 1 diabetes, type 2 diabetes, gestational diabetes mellitus (GDM), and other specific types of diabetes. ${ }^{2}$

For many years, GDM has been characterized as any degree of glucose intolerance recognized for the first time during pregnancy, regardless of whether the disease started before pregnancy or even persisted after pregnancy. This definition facilitated a uniform tracking strategy but was limited by imprecision. $^{2}$

Currently, there is an epidemic of obesity in the population of childbearing age, which creates the possibility of the pre-existence of type 2 diabetes with underdiagnosis. Thus, GDM is defined as diabetes diagnosed in the $2^{\text {nd }}$ or $3^{\text {rd }}$ trimester of pregnancy that was not clearly diabetes prior to pregnancy. ${ }^{3}$ Gestational DM occurs in 1 to $14 \%$ of all pregnancies and is related to increased perinatal morbidity and mortality. In Brazil, $\sim 7 \%$ of pregnancies are complicated by gestational hyperglycemia. ${ }^{1}$

The type of DM with the highest incidence in pregnancy is GDM, followed by pre-existing type 1 diabetes and type 2 diabetes. Regardless of the type of diabetes, the specific risks of uncontrolled diabetes in pregnancy include miscarriage, fetal abnormalities, pre-eclampsia, fetal death, macrosomia, neonatal hypoglycemia, and neonatal hyperbilirubinemia, among others. In addition, diabetes in pregnancy can increase the risk of obesity and type 2 diabetes in children born to diabetic mothers. ${ }^{3,4}$ During the fetal phase, the organs and tissues undergo critical periods of maturation, concomitantly with phases of rapid cell division. ${ }^{5}$

Fetal programming is characterized as a process by which a stimulus or insult, when received in the critical period of development, results in permanent repercussions on the 
structure and functions of the organism. ${ }^{6}$ Continuous transformations in the physiological processes of fetal programming can alter patterns of gene expression with influences on functions and phenotypes. ${ }^{6}$

It is estimated that nutrients can modify the immune and metabolic programming during sensitive periods of fetal and postnatal development. Among these nutrients, vitamin D stands out, since current observational studies suggest that it is essential for many physiological processes. ${ }^{7-9}$

With the vitamin definition, vitamin D3 or cholecalciferol can be synthesized by mammals from 7-dehydrocholesterol and through exposure to ultraviolet irradiation. Cholecalciferol or ergocalciferol (vitamin D2) can be obtained from dietary sources. In humans, cholecalciferol and ergocalciferol are sequentially transformed into 25-hydroxyvitamin D3 (25 OH VD), 25-hydroxycholecalciferol, or calcidiol, in the liver, and are subsequently transformed in the kidneys and other tissues into 1,25-dihydroxyvitamin D3 (1, 25 [OH] 2D), 1,25-dihydroxycholecalciferol or calcitriol. ${ }^{7-9}$

Vitamin D is responsible for maintaining calcium homeostasis and bone formation, including its relationship with the immune system. ${ }^{10}$ Vitamin D is known to have immunomodulatory and anti-inflammatory effects. ${ }^{11}$ Observational studies have shown a link between vitamin D deficiency and the onset and progression of type 2 diabetes. ${ }^{12,13}$

The literature points out that maternal vitamin $\mathrm{D}$ deficiency during pregnancy can have negative consequences for maternal and fetal health and is also associated with greater maternal and perinatal risks, such as: higher incidence of preeclampsia, insulin resistance, development of GDM, and increased frequency of cesarean delivery. $7,8,10-15$

Two recent meta-analyzes that aimed to assess the effects of vitamin D supplementation during the pregnancy of normoglycemic pregnant women on obstetric outcomes and birth variables reported that birthweight and newborn length were significantly higher for newborns in the supplemented group, with a mean difference of $107.6 \mathrm{~g}$ (95\% confidence interval [CI]: 59.9-155.3 g) and $0.3 \mathrm{~cm}$ (95\%CI: $0.10-0.41 \mathrm{~cm})$, respectively, and that the levels of $25(\mathrm{OH}) \mathrm{D}$ were significantly higher in the supplemented group, but the incidence of pre-eclampsia, GDM, low gestational age, low birthweight, premature birth, and cesarean section were not influenced by vitamin D supplementation, needing the elaboration of studies with larger populations to reach a definitive conclusion. ${ }^{16,17}$

A case-control study that included 4,718 women, designed to assess maternal blood serum concentrations of $25(\mathrm{OH}) \mathrm{D}$ and its association with GDM and other pregnancy outcomes, found that concentrations of $25(\mathrm{OH}) \mathrm{D}$ were significantly lower in pregnant women with GDM compared with the control group. After adjusting for confounding factors, women with low concentrations of $25(\mathrm{OH})$ D had a significantly increased risk of GDM and of some adverse pregnancy outcomes (anemia, macrosomia, abnormal amniotic fluid, and miscarriage or stillbirth). A threshold of 25(OH) D of $50.0 \mathrm{nmol}$ was also observed for the development of GDM. ${ }^{18}$

A recent systematic review with meta-analysis from randomized clinical trials, carried out by the authors of this same review sought to assess the effectiveness of vitamin D supple- ments used alone and in combination with calcium and vitamin supplements in pregnant women with GDM through the analysis of relevant maternal and neonatal parameters. The authors concluded that vitamin D supplementation in pregnant women with GDM may contribute to a decrease in fasting blood glucose (MD: -18.64 [-24.31-12.97]; $p<0.00001$ ), homeostasis model assessment for $\beta$-cell function (HOMA- $\beta$ ) and homeostasis model assessment for insulin resistance (HOMA-IR) (MD: -1.59 [-c2.20; -0.98$) ; p<0.00001$ ), serum calcium (MD: 0.60 [0.29-0.60]; $p=0.0002$ ), complications of the newborn, such as the occurrence of hyperbilirubinemia and polyhydramnios (MD: 0.34 [0.20-0.58]; $p<0.0001$ ), need for maternal hospitalization (MD: 0.13 [0.0-,0.98], $p=0.05$ ) and newborn hospitalization (MD: $0.40[0.23-0.68] ; p=0.0008$ ), and increased concentration of 25 (OH) D (MD: 16.63 [11.46-21.80); $p<0.00001$ ). However, these results should be interpreted with caution, as the quality of the evidence obtained through the Grading of Recommendations, Assessment, Development and Evaluations (GRADE) tool was very low and the studies included in the review present a risk of high bias and small sampling. The effect of vitamin D when combined with other vitamins and minerals should be clarified. Therefore, other randomized clinical trials with placebo should be designed to highlight the possible benefits of supplementation for pregnant women with GDM. ${ }^{19}$

A cohort study that aimed to determine vitamin $\mathrm{D}$ levels after pregnancies affected by GDM and to verify its association with $\beta$ cell function, insulin resistance or diabetes diagnosis in the future. This study identified that low levels of $25(\mathrm{OH}) \mathrm{D} 3$ were common up to 2 years after the occurrence of GDM. The study suggests that vitamin D deficiency/insufficiency appears to be associated with $\beta$ cell dysfunction and insulin resistance. However, no association has been reported between vitamin $D$ levels and the development of type 2 diabetes, and further studies are needed in the future for clarification. ${ }^{20}$

Women who have developed GDM often have postpartum glucose intolerance, as well as increased insulin resistance after delivery, compared with normoglycemic women. Increased insulin resistance is likely to increase the risk of metabolic syndrome and of type 2 diabetes in subsequent years. Thus, postpartum vitamin D supplementation in women with GDM can be suggested as an intervention to protect against $\beta$ cell dysfunction, insulin resistance, and the diagnosis of type 2 diabetes in the future. In view of the above, the present review aimed to evaluate the effects of vitamin D supplementation in the postpartum period of pregnant women with previous GDM.

\section{Methods}

\section{Protocol and Registration}

This is a bibliographic study, a systematic review with metaanalysis performed according to the Cochrane methodology. ${ }^{21}$ The present systematic review had its protocol published in the PROSPERO (International prospective register of systematic reviews) database under the CRD42018110729 ${ }^{22}$ register and followed the rules of the Preferred Reporting Items for Systematic Reviews and Meta-Analyses (PRISMA) checklist. ${ }^{23}$ 


\section{Eligibility Criteria}

Randomized clinical trials (RCTs) that evaluated the effects of vitamin D supplementation in the postpartum period of pregnant women with previous GDM were selected, with 3 months of follow-up and with evaluation of the results in the postpartum period, in which the patients were randomly distributed into two groups: intervention group and control group, following the PICO methodology described below. Population: pregnant women diagnosed with GDM who received vitamin $D$ supplementation in the prenatal or postpartum period. Intervention: effect of vitamin D supplementation in the postpartum period. Comparator: no supplementation and/or placebo. Outcomes: serum vitamin $D$ concentration (25-hydroxyvitamin $\mathrm{D}$ in $\mathrm{nmol} / \mathrm{L}$ ), fasting glucose, glycated hemoglobin, serum calcium concentration, HOMA-IR, quantitative insulin sensitivity check index (QUICKI), parathyroid hormone (PTH), and body mass index (BMI).

\section{Inclusion and Exclusion Criteria}

The present study evaluated vitamin D supplementation in the postpartum period, used alone and in combination with calcium and vitamin supplements, on the maternal results of pregnant women with previous GDM. Randomized clinical trials of pregnant women with GDM of any chronological, gestational age and parity, with no history of previous disease who received vitamin $\mathrm{D}$ supplementation in the prenatal and/or the postpartum period and were evaluated in the postpartum period were included. The intervention of interest was: vitamin $D$ isolated in the postpartum versus no prenatal and/or postpartum placebo treatment or administration. Intervention and control can be administered by any means. The exclusion criteria were: evaluation of the pregnant woman in the prenatal period, $<3$ months of follow-up, and nonrandomization between the groups.

\section{Search Strategy}

The following electronic databases were consulted: the National Center for Biotechnology Information (NCBI/PubMed) (1966-July 2019), Embase (1980-March 2019), Cochrane Library (1972-July 2019), Latin American Literature and Caribbean Health Sciences (LILACS) (1982-July 2019), and the Virtual Health Library (VHL) website. Information on ongoing clinical trials was retrieved through the clinical trials website (http://clinicaltrials.gov) of the National Health Institute and through the Brazilian Registry of Clinical Trials (ReBEC, in the Portuguese acronym) (http://www.ensaiosclinicos.gov.br/). The basic search strategy was developed for PubMed and was modified as needed for other databases (-Appendix $\mathbf{1}$ ). The health descriptors available in Health Sciences Descriptors (DECs) and Medical Subject Heading (MeSH) were used. The descriptors used included gestational diabetes, postpartum period, vitamin $D$, and cholecalciferol. There was no language restriction, but only human studies were selected. References of selected articles, including relevant review articles, were reviewed to identify all relevant studies. Manual search for references of clinical trials in relevant journals was performed.

\section{Selection of Studies and Data Extraction}

For the present review, two researchers independently reviewed the eligibility of the titles and summaries. Disagreements regarding the selection of articles were resolved either by consensus or by discussion with a third investigator. The study selection flowchart was created in accordance with the PRISMA guidelines. ${ }^{23}$

Two researchers independently extracted the relevant data (participants, specific vitamin D intervention, and outcome characteristics) from each full-text article using a standardized form based on the Cochrane Handbook ${ }^{21}$ with the following information: study characteristics (design, randomization method); participants; interventions; clinical outcomes (types of outcomes measured, that is, dichotomous or continuous; adverse effects). The selection was compared for accuracy, and any discrepancies were resolved either by consensus or by discussion with another investigator.

\section{Bias Risk Assessment}

Two investigators independently assessed the risk of bias for each eligible RCT. Discrepancies were resolved either by consensus or by discussion with another investigator. The Cochrane Collaboration tool was used to assess the risk of bias in RCTs. ${ }^{24}$ Thus, the items evaluated were: generation of the allocation sequence (selection bias); hiding the allocation sequence (bias selection); blinding (detection and performance bias); blinding of participants and staff for evaluation of results; incomplete result data (attrition bias); selective reporting result (information bias). For each RCT, the items were described and presented as low risk of bias, risk of uncertain bias or high risk of bias according to the classification obtained.

\section{Data Analysis}

For the analysis, fixed and random effects models (when necessary) and the Mantel-Haenszel method were used. Associations were reported as relative risks (RR) and their 95\% confidence intervals (Cls). Standard deviation (SD) was calculated when the interquartile range (IQR) was available. Heterogeneity was tested with the Cochrane $x^{2}$ test, and the degree of heterogeneity was quantified with the I2 statistic and its $95 \% \mathrm{Cl}$. An I2 value between 30 and $60 \%$ was described as moderate heterogeneity. Publication bias was assessed with the funnel plots and formally tested with the Egger test. For the variability in results between studies, the I2 statistic and the p-value obtained from the chi-squared Cochrane test were used. Review Manager (RevMan) software was used for all analyzes (version 5.3; Nordic Cochrane Center, Cochrane). ${ }^{25}$ Conversion factor: $1 \mathrm{mmol} / \mathrm{L}=18.018$ $\mathrm{mg} / \mathrm{dL} ; \mathrm{pg} / \mathrm{ml}$ was converted to $\mathrm{pmol} / \mathrm{l}$ when necessary.

\section{Assessment of the Quality of Evidence}

The evaluation of the quality of the evidence was made with the GRADE tool ${ }^{26}$ for the outcomes serum vitamin D concentration (25-hydroxyvitamin D in $\mathrm{nmol} / \mathrm{L}$ ), fasting glycemia, glycated hemoglobin, serum concentration of calcium, HOMA-IR, QUICKI, PTH and BMI. 


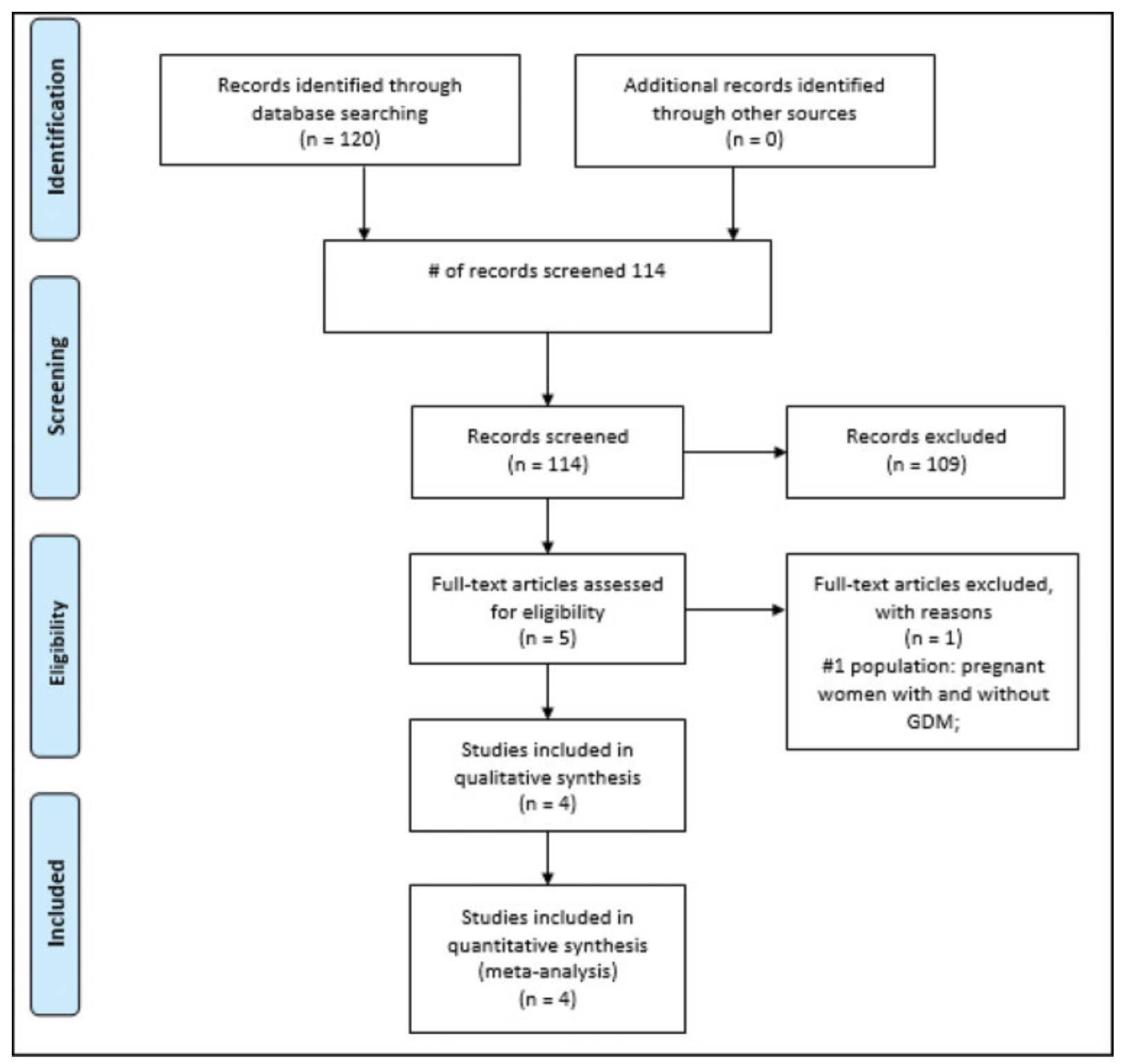

Fig. 1 Flowchart for identifying eligible studies.

\section{Results}

\section{Selected Articles}

After searching the electronic health databases, 120 references were identified. Seven articles were potentially eligible for inclusion in the present review and, therefore, were read in full. After reading and critical analysis, four articles were selected for qualitative and quantitative analysis (meta-analysis). The gray literature did not report any findings according to the eligibility criteria (-Fig. $\mathbf{1}$ ).

After being read in full, four studies met the inclusion criteria and were included in the present systematic review. ${ }^{27-30}$ One study was excluded because its population included women without a previous diagnosis of GDM. ${ }^{31}$

\section{Description of the Studies}

The 4 included RCTs totaled 200 pregnant women diagnosed with previous GDM who received vitamin D supplementation in the prenatal or postpartum period. ${ }^{27-30}$ In two articles, supple- mentation occurred during prenatal care, ${ }^{27,29}$ and, in the other two, supplementation was administered in the postpartum period, ${ }^{28,30}$ but all analyzes were performed in the postpartum period. In only one study there placebo was administered in the control group, while in the intervention group $4000 \mathrm{IU}$ of vitamin D3 (cholecalciferol) per day (4 capsules of $1000 \mathrm{IU}$ each) were administered for 6 months; in the control group, placebo was administered similarly to Vitamin D3 in the intervention group. ${ }^{28}$ Another study that administered vitamin D supplementation (25-hydroxyvitamin D in nmol/L) orally, through the administration of capsules, had an intervention of 200,000 IU of vitamin D3 in the first 2 days after randomization, followed by $50,000 \mathrm{IU}$ per week thereafter, up to a total of 700,000 IU. Women randomized at $\geq 28$ weeks of gestation received 100,000 IU weekly. ${ }^{27}$ In the other 2 studies, the control group also did not receive a placebo while individuals in the intervention group received a single-dose intramuscular injection containing 300,000 IU of vitamin D3. ${ }^{29,30}$ Chart 1 describes the characteristics of the studies included in the analysis. 
704 Supplementation of Vitamin D in the Postdelivery Period of Women Kron-Rodrigues et al.

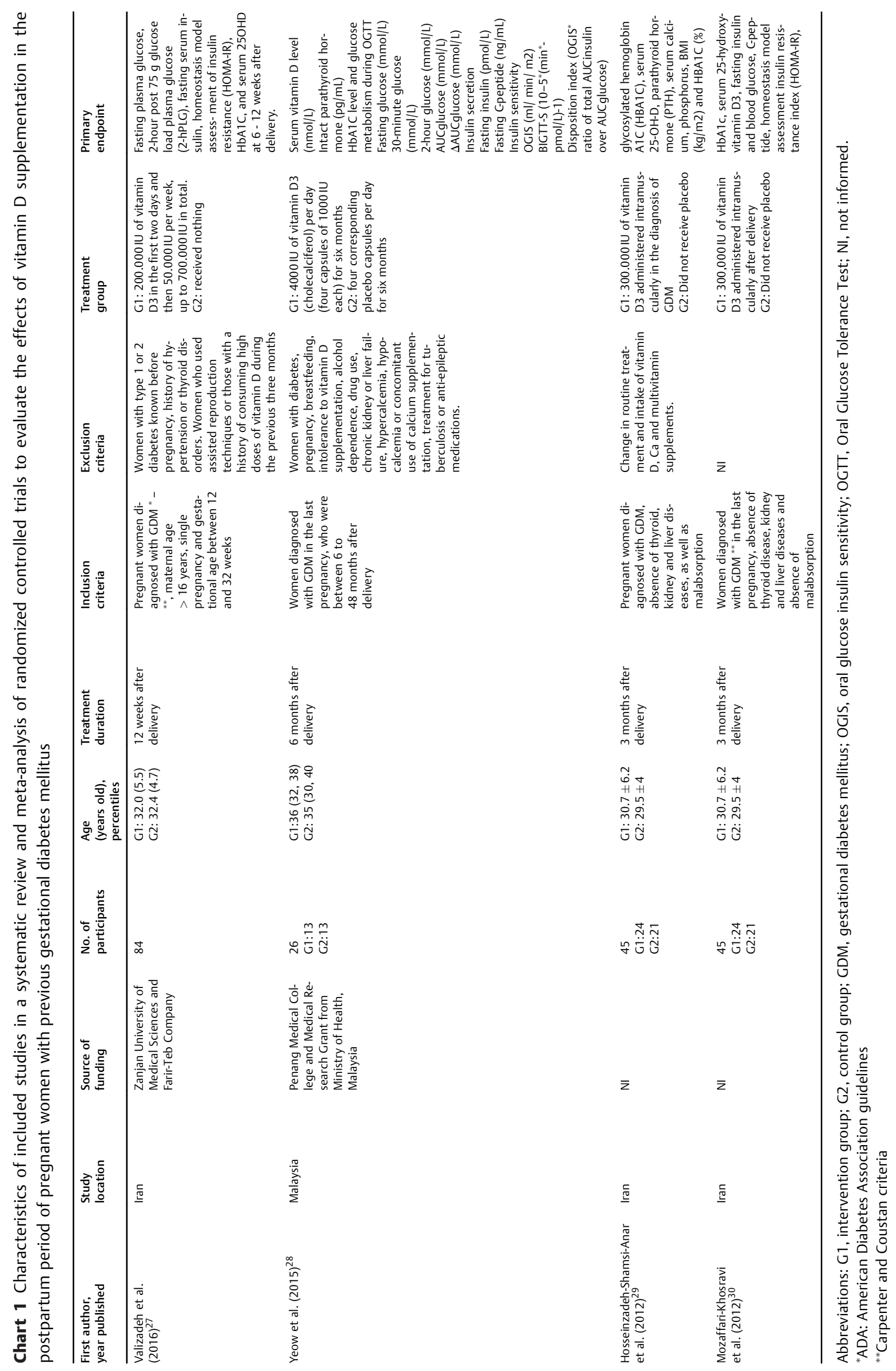




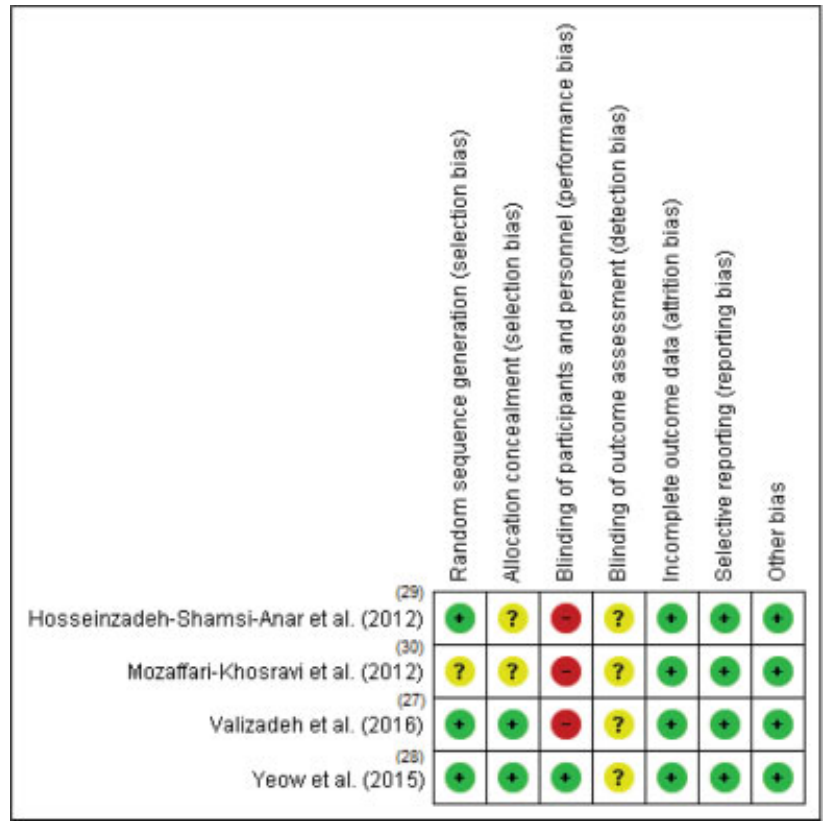

Fig. 2 Assessment of bias risk of randomized clinical trials included.

\section{Risk of Bias}

The risk of bias assessment is summarized in - Fig. 2. Regarding the randomization process, three ${ }^{27-29}$ studies were considered as of low risk, since one reported the use of computer software to generate the random sequence for randomization ${ }^{28}$ and two reported the use of a table of random numbers. ${ }^{27,29}$ One study was classified as of uncertain risk, as it did not report the randomization process. ${ }^{30}$

In the allocation concealment, two ${ }^{29,30}$ studies were considered uncertain because they did not report the process and two ${ }^{27,28}$ were of low risk, since one reported that the concealment was preserved by the existence of opaque envelopes numbered sequentially ${ }^{27}$ and the other study was considered low risk because reported that the drugs were number in a different way sequential with identical appearance. ${ }^{28}$

Regarding the blinding of participants and professionals, three $27,29,30$ studies included in the present review were considered as of high risk, since no placebo was administered in the control group. One study ${ }^{28}$ was considered as of low risk because placebo was administered at the same dose as the intervention and there is evidence that randomization and allocation were hidden from investigators and subjects until the study was completed.

In the blinding outcome evaluation, the four ${ }^{27-30}$ studies were considered uncertain because they did not report this information.
Regarding incomplete outcomes, the four ${ }^{27-30}$ studies were considered as of low risk, with one ${ }^{28}$ reporting performing analysis by intention to treat and three ${ }^{27,29,30}$ describing their losses and reasons, with balanced data losses between groups, with similar reasons for data loss between groups.

For reporting a selective outcome, the four ${ }^{27-30}$ studies were classified as of low risk of bias, with two ${ }^{28,29}$ studies with records and results compatible with those initially proposed and two ${ }^{27,30}$ studies that, even without records, reported outcomes compatible with the intervention. Regarding other sources of bias, they were not identified in any study, with the four studies ${ }^{27-30}$ being classified as of low risk of bias.

\section{Meta-analysis}

Serum vitamin D concentration (25-hydroxyvitamin D in $\mathrm{nmol} / \mathrm{L}$ ), fasting glycemic parameters, glycated hemoglobin, serum calcium concentration, HOMA-IR, QUICKI, PTH, and BMI were considered primary outcomes. The four ${ }^{27-30}$ studies included in the present review analyzed the serum concentration of vitamin D after follow-up, where the meta-analysis identified that in the group that received vitamin $\mathrm{D}$ in the prenatal and/or in the postpartum period, but were analyzed later, there was a significant increase in the serum concentration of vitamin $\mathrm{D}$ in the intervention group (RR: 1.85 ; 95\%CI: 1.02-2.68), but with high heterogeneity $(\mathrm{I} 2=81 \%$ ) between the studies ( - Fig. 3 ).

Fasting blood glucose levels were reported in three $27,28,30$ articles and demonstrated no difference between the control and intervention groups that received vitamin D supplementation in the postpartum period of pregnant women with previous GDM (RR: -0.02 ; 95\%CI: $-0.54-0.51$ ), showing medium heterogeneity $(\mathrm{I} 2=58 \%)$ between the studies (-Fig. 4).

The outcome was glycated hemoglobin across all ${ }^{27-30}$ studies and showed no significant difference between groups (RR: 0.21 ; 95\%CI: $-0.06-0.49)$ with null heterogeneity $(\mathrm{I} 2=0 \%$ ) between the studies ( $\mathbf{- F i g . ~} \mathbf{5}$ ).

For serum calcium concentration, there was an analysis in three studies, ${ }^{27,29,30}$ in which the meta-analysis showed no statistically significant difference between the groups (RR: 0.02 ; 95\%CI: - 0.32-0.27) with null heterogeneity ( $\mathrm{I} 2=0 \%)$ between the studies (-Fig. 6 ).

The HOMA-IR outcome was reported in $2^{30}$ studies and showed no significant difference between groups (RR: 0.13; 95\%CI: - 0.22-0.47) with null heterogeneity ( $\mathrm{I} 2=0 \%$ ) between the studies ( - Fig. 7).

The QUICKI outcome was also reported in $2^{30}$ studies and showed no significant difference between groups (RR: - 0.10;

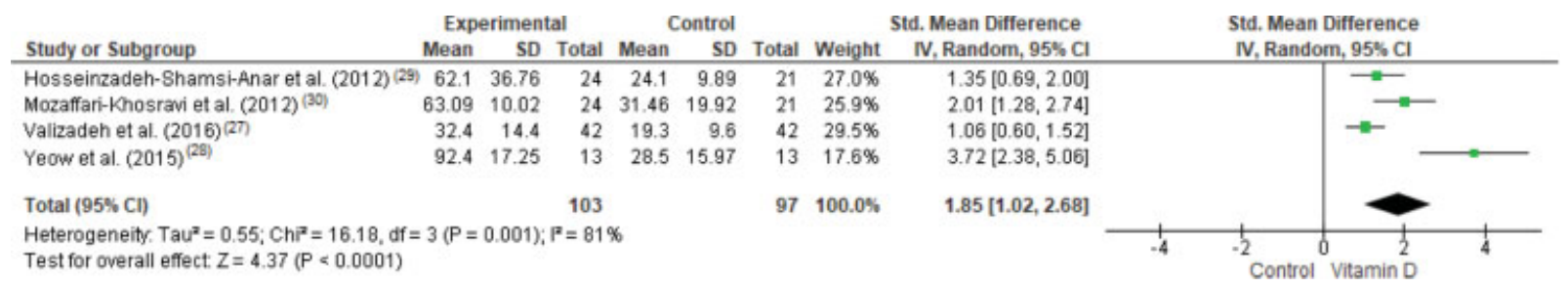

Fig. 3 Meta-analysis of serum vitamin D concentration. 


\begin{tabular}{|c|c|c|c|c|c|c|c|c|c|}
\hline \multirow[b]{2}{*}{ Study or Subgroup } & \multicolumn{3}{|c|}{ Experimental } & \multicolumn{3}{|c|}{ Control } & \multicolumn{2}{|c|}{ Std. Mean Difference } & \multirow{2}{*}{$\begin{array}{l}\text { Std. Mean Difference } \\
\text { IV, Random, } 95 \% \mathrm{Cl}\end{array}$} \\
\hline & Mean & SD & Total & Mean & SD & Total & Weight & IV, Random, $95 \% \mathrm{Cl}$ & \\
\hline Mozaffari-Khosrawi et al. $(2012)^{(30)}$ & 92.9 & 10.6 & 24 & 104.7 & 33.5 & 21 & $33.0 \%$ & $-0.48[-1.08,0.11]$ & \\
\hline Valizadeh et al. $(2016)(27)$ & 94 & 16 & 42 & 89 & 13 & 42 & $41.3 \%$ & $0.34[-0.09,0.77]$ & \\
\hline Yeow et al. (2015) (28) & 86.44 & 0.44 & 13 & 86.44 & 0.74 & 13 & $25.7 \%$ & $0.00[-0.77,0.77]$ & \\
\hline Total $(95 \% \mathrm{Cl})$ & & & 79 & & & 76 & $100.0 \%$ & $-0.02[-0.54,0.51]$ & \\
\hline $\begin{array}{l}\text { Heterogeneity: } \text { Tau }^{2}=0.12 ; \mathrm{Ch}^{2}= \\
\text { Test for overall effect: } Z=0.07 \text { (P }\end{array}$ & $\begin{array}{l}=4.81, \mathrm{c} \\
=0.95)\end{array}$ & $\mathrm{ff}=2$ & $P=0.0$ & $9) ; 1^{2}=5$ & & & & & $\begin{array}{cccc}-2 & -1 & 0 & 1 \\
& -1 & 1 \\
& \text { Vitamin } & & \\
& \text { Control }\end{array}$ \\
\hline
\end{tabular}

Fig. 4 Meta-analysis of fasting blood glucose.

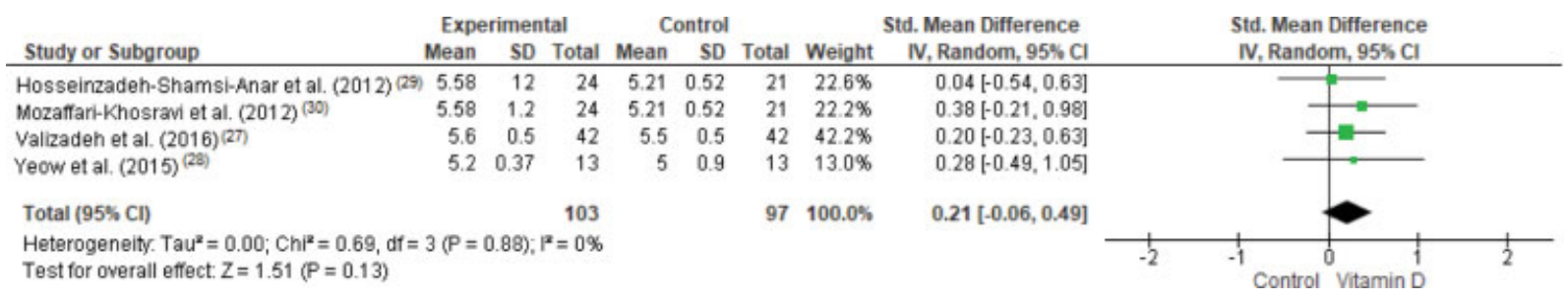

Fig. 5 Meta-analysis of glycated hemoglobin.

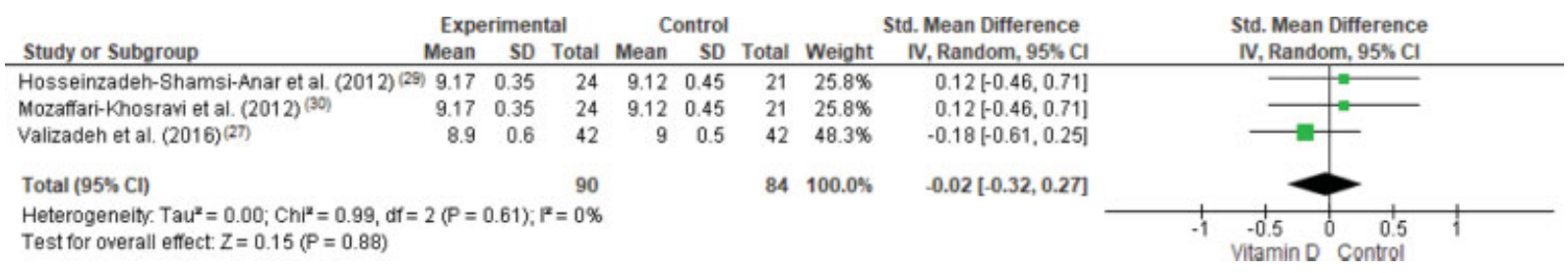

Fig. 6 Meta-analysis serum calcium concentration.

\begin{tabular}{|c|c|c|c|c|c|c|c|c|c|c|}
\hline \multirow[b]{2}{*}{ Study or Subgroup } & \multicolumn{3}{|c|}{ Experimental } & \multicolumn{3}{|c|}{ Control } & \multicolumn{2}{|c|}{ Std. Mean Difference } & \multirow{2}{*}{\multicolumn{2}{|c|}{$\begin{array}{l}\text { Std. Mean Difference } \\
\text { IV, Random, } 95 \% \mathrm{Cl}\end{array}$}} \\
\hline & Mean & SD & Total & Mean & SD & Total & Weight & IV, Random, $95 \% \mathrm{Cl}$ & & \\
\hline Mozaffari-Khosravi et al. (2012) (30) & 0.63 & 0.22 & 24 & 0.6 & 0.22 & 21 & $34.8 \%$ & $0.13[-0.45,0.72]$ & - & \\
\hline Valizadeh et al. $(2016)(27)$ & 2 & 1.3 & 42 & 1,8 & 1.9 & 42 & $65.2 \%$ & $0.12[-0.31,0.55]$ & & \\
\hline Total $(95 \%$ Cl) & & & 66 & & & 63 & $100.0 \%$ & $0.13[-0.22,0.47]$ & & \\
\hline $\begin{array}{l}\text { Heterogeneity. } \text { Tau }^{2}=0.00 ; \mathrm{Chi}^{2}= \\
\text { Test for overall effect } Z=0.71(P=\end{array}$ & $\begin{array}{l}=0.00, \\
=0.48)\end{array}$ & $f=1$ & $P=0.9$ & $7) ; 1^{2}=0$ & & & & & -1 Vitamin D Control & 1 \\
\hline
\end{tabular}

Fig. 7 Meta-analysis HOMA-IR.

\begin{tabular}{|c|c|c|c|c|c|c|c|c|c|}
\hline \multirow[b]{2}{*}{ Study or Subgroup } & \multicolumn{3}{|c|}{ Vitamin D } & \multicolumn{3}{|c|}{ Control } & \multicolumn{2}{|c|}{ Std. Mean Difference } & \multirow{2}{*}{$\begin{array}{l}\text { Std. Mean Difference } \\
\text { IV, Random, } 95 \% \mathrm{Cl}\end{array}$} \\
\hline & Mean & SD & Total & Mean & SD & Total & Weight & IV, Random, $95 \% \mathrm{Cl}$ & \\
\hline Mozaffari-Khosravi et al. $(2012){ }^{(30)}$ & 0.38 & 0.02 & 24 & 0.36 & 0.02 & 21 & $50.9 \%$ & $0.98[0.36,1.61]$ & \begin{tabular}{l|l}
- & -2 \\
-
\end{tabular} \\
\hline Yeow et al. $(2015)^{(28)}$ & 0.31 & 0.01 & 13 & 0.33 & 0.02 & 13 & $49.1 \%$ & $-1.22[-2.07,-0.38]$ & -1 \\
\hline Total $(95 \% \mathrm{Cl})$ & & & 37 & & & 34 & $100.0 \%$ & $-0.10[-2.26,2.06]$ & \\
\hline \multicolumn{9}{|c|}{$\begin{array}{l}\text { Heterogeneity: } \text { Tau }^{2}=2.29 ; \mathrm{Ch}^{2}=16.87, \mathrm{df}=1(\mathrm{P}<0.0001) ; \mathrm{P}^{2}=94 \% \\
\text { Test for overall effect: } Z=0.09(P=0.93)\end{array}$} & $\begin{array}{cccc}-4 & -2 & 0 & 2 \\
\text { Vitamin D Control }\end{array}$ \\
\hline
\end{tabular}

Fig. 8 Meta-analysis QUICKI.

95\%CI: - 2.26-2.06) with high heterogeneity (I2=94\%) between the studies (-Fig. 8).

Parathyroid hormone was analyzed in $2^{29}$ studies and showed no significant difference between groups (RR: - 0.42; 95\%CI: - 1.66-0.82) with high heterogeneity (I2=84\%) between the studies (-Fig. 9).

Body mass index was analyzed in $3^{29,30}$ studies and did not show a significant difference between the groups (RR: 0.21 ; 95\%CI: - 0.09-0.51) with null heterogeneity (I2=0\%) between the studies (-Fig. 10).

\section{Evaluation of Quality of Evidence According to the GRADE framework}

The evaluation of the quality of the evidence was performed for the outcomes serum vitamin D concentration (25-hydroxyvitamin D in nmol/L), fasting blood glucose, glycated hemoglobin, HOMA-IR, QUICKI, PTH, all of which are classified as very low quality of evidence. As $<10$ RCTs were included in the present review, it was not possible to analyze the presence of publication bias (-Table 1 ). 


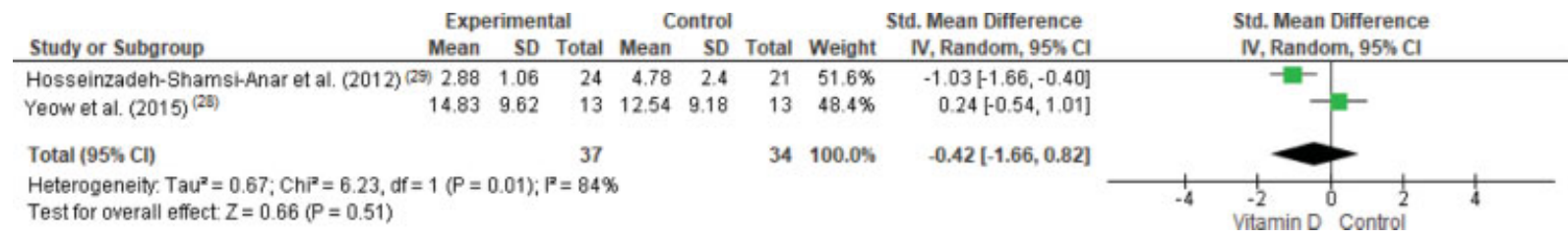

Fig. 9 Meta-analysis of parathyroid hormone (PTH).

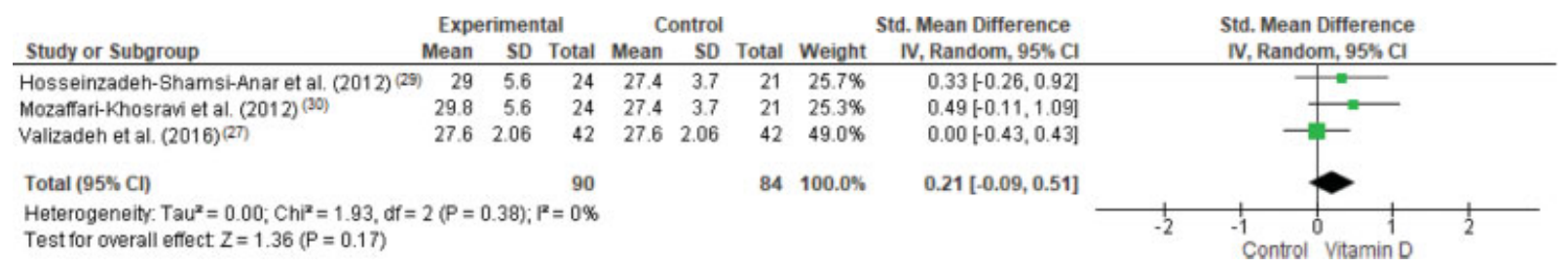

Fig. 10 Meta-analysis of body mass index (BMI).

Table 1 Summary of findings based on the GRADE framework

\begin{tabular}{|c|c|c|c|c|c|c|c|}
\hline Outcomes & $\begin{array}{l}\text { Patients } \\
\text { (n) }\end{array}$ & $\begin{array}{l}\text { Risk of } \\
\text { bias }\end{array}$ & Inconsistency & Indirectness & Imprecision & $\begin{array}{l}\text { Publication } \\
\text { bias }\end{array}$ & $\begin{array}{l}\text { Quality of } \\
\text { evidence }\end{array}$ \\
\hline \multicolumn{8}{|c|}{ Serum vitamin D concentration } \\
\hline & $\begin{array}{l}200 \\
\text { (4 RCTs) }\end{array}$ & Serious $(-1)^{*}$ & $\begin{array}{l}\text { Very serious }{ }^{\text {a }} \\
(-2)^{*}\end{array}$ & Not serious & $\begin{array}{l}\text { Serious }^{b} \\
(-1)^{*}\end{array}$ & Probably not & $\oplus \bigcirc \bigcirc \bigcirc$ very low \\
\hline \multicolumn{8}{|c|}{ Fasting blood glucose } \\
\hline & $\begin{array}{l}132 \\
\text { (3 RCTs) }\end{array}$ & Serious $(-1)^{*}$ & $\begin{array}{l}\text { Serious }^{\mathrm{a}} \\
(-1)\end{array}$ & Not serious & $\begin{array}{l}\text { Serious }^{b} \\
(-1)^{*}\end{array}$ & Probably not & $\oplus \bigcirc \bigcirc \bigcirc$ very low \\
\hline \multicolumn{8}{|c|}{ Glycated hemoglobin } \\
\hline & $\begin{array}{l}200 \\
(4 \mathrm{RCTs})\end{array}$ & Serious $(-1)^{*}$ & Not serious & Not serious & $\begin{array}{l}\text { Very serious } \\
(-2)^{*}\end{array}$ & Probably not & $\oplus \bigcirc \bigcirc \bigcirc$ very low \\
\hline \multicolumn{8}{|l|}{ HOMA-IR } \\
\hline & $\begin{array}{l}129 \\
\text { (2 RCTs) }\end{array}$ & Serious $(-1)^{*}$ & Not serious & Not serious & Very serious $(-2)^{*}$ & Probably not & $\oplus \bigcirc \bigcirc \bigcirc$ very low \\
\hline \multicolumn{8}{|l|}{ QUICKIE } \\
\hline & $\begin{array}{l}68 \\
\text { (2 ECR's) }\end{array}$ & Serious $(-1)^{*}$ & $\begin{array}{l}\text { Very serious }{ }^{a} \\
(-2)^{*}\end{array}$ & Not serious & Not serious & Probably not & $\oplus \bigcirc \bigcirc \bigcirc$ very low \\
\hline \multicolumn{8}{|l|}{ PTH } \\
\hline & $\begin{array}{l}71 \\
\text { (2 ECR's) }\end{array}$ & $\begin{array}{l}\text { Grave } \\
(-1)^{*}\end{array}$ & $\begin{array}{l}\text { Very serious }{ }^{a} \\
(-2)^{*}\end{array}$ & Not serious & Not serious & Probably not & $\oplus \bigcirc \bigcirc \bigcirc$ very low \\
\hline
\end{tabular}

a. High heterogeneity between studies, b. Amplitude in the $95 \%$ confidence interval

Note: To determine a GRADE quality of the evidence, the GRADE approach begins by assigning findings to one of the two initial levels of quality, depending on the study design. Randomized trials are of high quality, while observational studies are of low quality. The evidence can be considered at four levels: high, moderate, low, and very Low. Studies can be updated or downgraded based on certain factors:

a) Risk of bias ( -1 if serious risk of bias, -2 if very serious risk of bias).

b) Inconsistency or heterogeneity of evidence ( -1 if serious inconsistency, - 2 if very serious inconsistency)

c) Indirectness of evidence ( -1 if serious, -2 if very serious)

d) Imprecision of results ( -1 if wide confidence interval, -2 if very wide confidence interval)

e) Publication bias (- 1 if likely, -2 if very likely) *Small events and a large confidence interval. Low quality of evidence: the authors do not trust the estimate of the effect and the actual value may differ substantially from this.

\section{Discussion}

In the literature, the present article is the first systematic review evaluating the effects of vitamin D supplementation in the postpartum period of pregnant women with previous GDM.

Previously, a systematic review with meta-analysis performed by at least one research group aimed to assess whether vitamin D supplementation administered to pregnant women with GDM would improve maternal and neo- natal outcomes and found no evidence of moderate or high quality indicating that vitamin D supplementation, when compared with placebo, improves glucose metabolism or adverse maternal and neonatal outcomes related to GDM. ${ }^{19}$

Our findings indicate that there is no difference in the postpartum period in women diagnosed with previous GDM who received vitamin D supplementation in the prenatal and/or in the postpartum period, showing only that there was a significant increase in the concentration of vitamin D 
(RR: 1.85 ; 95\%CI: 1.02-2.68). This increase in the concentration of vitamin $\mathrm{D}$ should be interpreted with caution, since the assessment of the quality of the evidence was very low. For the other outcomes analyzed, there was no significance between the intervention and control groups.

The present systematic review has limitations, the main one being related to the small number of clinical trials and of women included in the analysis. The option to include only RCTs can also be a limiting factor for the analyzes; however, the choice was based on the search for studies that reported the best design to obtain the best available evidence.

The small number of clinical trials included resulted in a small population analyzed, and this factor contributed to the extensive CIs between the studies.

The methodological quality of RCTs can also be considered a limiting factor, since the selected studies have questionable methodological biases. The fact that two studies did not administer a placebo in the control group made it impossible to blind participants and researchers.

\section{Conclusion}

No moderate or high-quality evidence was found in the included RCTs that prove that there are favorable effects of vitamin D supplementation in the postpartum period of pregnant women with previous GDM. Thus, there is no evidence to suggest that vitamin $D$ supplementation may be a protective factor against $\beta$ cell dysfunction, insulin resistance and the diagnosis of type 2 diabetes in the future. The development of well-designed RCTs with the inclusion of large populations is recommended, as well as the use of placebos in the control group to verify the efficacy and safety of vitamin D supplementation in the postpartum period of pregnant women with previous GDM with the aim of to verify whether supplementation can beneficially assist in maintaining $\beta$ cell function, in reducing insulin resistance and, in the future, reducing the incidence of type 2 diabetes.

\section{Conflict of Interests}

The authors have no conflict of interests to declare.

\section{Acknowledgments \\ Rodrigues M. R. K-R. - CAPES (Coordination for the Improve- ment of Higher Level-or Education-Personnel) postdoctoral fellowship scholarship holder. The funders had no role in the study design, data collection and analysis, decision to pub- lish, or preparation of the manuscript.}

\section{References}

1 Oliveira JE, Vencio Sorganizadores. Diretrizes da Sociedade Brasileira de Diabetes: 2015-2016. São Paulo: A.C. Farmacêutica; 2016

2 American Diabetes Association. 2. Classification and diagnosis of diabetes: standards of medical care in diabetes-2020. Diabetes Care. 2020;43(Suppl 1):S14-S31. Doi: 10.2337/dc20-S002

3 American Diabetes Association. 1. Improving care and promoting health in populations: standards of medical care in diabetes2020. Diabetes Care. 2020;43(Suppl 1):S7-S13. Doi: 10.2337/ dc20-S001
4 American Diabetes Association. 14. Management of diabetes in pregnancy: standards of medical care in diabetes-2020. Diabetes Care. 2020;43(Suppl 1):S183-S192. Doi: 10.2337/dc20-S014

5 Cunningham S, Cameron IT. Consequences of fetal growth restriction during childhood and adult life. Curr Obstet Gynaecol. 2003; 13(04):212-217. Doi: 10.1016/S0957-5847(03)00039-8

6 Leandro CG, Amorim MF, Hirabara SM, Curi R, Castro RM. Pode a atividade física materna modular a programação fetal induzida pela nutrição? Rev Nutr. 2009;22(04):559-569. Doi: 10.1590/ S1415-52732009000400011

7 Urrutia-Pereira M, Solé D. Vitamin D deficiency in pregnancy and its impact on the fetus, the newborn and in childhood. Rev Paul Pediatr. 2015 Jan-Mar;33(01):104-113. Doi: 10.1016/j.rpped.2014.05.004. Epub 2015 Feb 7. PMID: 25662013; PMCID: PMC4436962

8 Pérez-López FR, Chedraui P, Fernández-Alonso AM. Vitamin D and aging: beyond calcium and bone metabolism. Maturitas. 2011;69 (01):27-36. Doi: 10.1016/j.maturitas.2011.02.014

9 Wacker M, Holick MF. Vitamin D - effects on skeletal and extraskeletal health and the need for supplementation. Nutrients. 2013;5(01):111-148. Doi: 10.3390/nu5010111

10 Ponsonby AL, Lucas RM, Lewis S, Halliday J. Vitamin D status during pregnancy and aspects of offspring health. Nutrients. 2010;2(03):389-407. Doi: 10.3390/nu2030389

11 Krul-Poel YH, Ter Wee MM, Lips P, Simsek S. MANAGEMENT OF ENDOCRINE DISEASE: The effect of vitamin D supplementation on glycaemic control in patients with type 2 diabetes mellitus: a systematic review and meta-analysis. Eur J Endocrinol. 2017;176 (01):R1-R14. Doi: 10.1530/EJE-16-0391

12 Chagas CE, Borges MC, Martini LA, Rogero MM. Focus on vitamin D, inflammation and type 2 diabetes. Nutrients. 2012;4(01): 52-67. Doi: 10.3390/nu4010052

13 Song Y, Wang L, Pittas AG, Del Gobbo C, Zhang C, Manson JE, et al. Blood 25-hydroxy vitamin D levels and incident type 2 diabetes: a meta-analysis of prospective studies. Diabetes Care. 2013;36(05): 1422-1428. Doi: 10.2337/dc12-0962

14 Grimnes G, Emaus N, Joakimsen RM, Figneshau Y, Jenssen TNjølstad. et al. Baseline serum 25-hydroxyvitamin D concentrations in the Tromsø Study 1994-95 and risk of developing type 2 diabetes mellitus during 11 years of follow-up. Diabet Med. 2010;27(10): 1107-1115. Doi: 10.1111/j.1464-5491.2010.03092.x

15 Thorne-Lyman A, Fawzi WW. Vitamin D during pregnancy and maternal, neonatal and infant health outcomes: a systematic review and meta-analysis. Paediatr Perinat Epidemiol. 2012;26 (Suppl 1):75-90. Doi: 10.1111/j.1365-3016.2012.01283.x

16 Palacios C, De-Regil LM, Lombardo LK, Peña-Rosas JP. Vitamin D supplementation during pregnancy: Updated meta-analysis on maternal outcomes. J Steroid Biochem Mol Biol. 2016; 164:148-155. Doi: 10.1016/j.jsbmb.2016.02.008

17 Pérez-López FR, Pasupuleti V, Mezones-Holguin E, Benites-Zapata VA, Thota P, Deshpande A, et al. Effect of vitamin D supplementation during pregnancy on maternal and neonatal outcomes: a systematic review and meta-analysis of randomized controlled trials. Fertil Steril. 2015;103(05):1278-88.e4. Doi: 10.1016/j. fertnstert.2015.02.019

18 Wen J, Hong Q, Zhu L, Xu P, Fu Z, Cui X, et al. Association of maternal serum 25-hydroxyvitamin $D$ concentrations in second and third trimester with risk of gestational diabetes and other pregnancy outcomes. Int J Obes. 2017;41(04):489-496. Doi: 10.1038/ijo.2016.227

19 Rodrigues MRK, Lima SAM, Mazeto GMFDS, Calderon IMP, Magalhães CG, Ferraz GAR, et al. Efficacy of vitamin D supplementation in gestational diabetes mellitus: Systematic review and meta-analysis of randomized trials. PLoS One. 2019;14(03): e0213006. Doi: 10.1371/journal.pone.0213006

20 Shaat N, Ignell C, Katsarou A, Berntorp K. Glucose homeostasis, beta cell function, and insulin resistance in relation to vitamin $\mathrm{D}$ status after gestational diabetes mellitus. Acta Obstet Gynecol Scand. 2017;96(07):821-827. Doi: 10.1111/aogs.13124 
21 Higgins JP, Green S, Eds. Cochrane handbook for systematic reviews of interventions version 5.1.0 [Internet]. London: The Cochrane Collaboration; 2011 [cited 2019 Dec 12]. Available from: https://handbook-5-1.cochrane.org/

22 Rodrigues M, Molina AC, Ferraz GA, Lima SA. Supplementation of vitamin $\mathrm{D}$ in the postpartum period of women with previous diabetes mellitus gestational: systematic review of randomized clinical trials [Internet]. PROSPERO 2018 [cited 2019 Dec 12]. Available from: https://www.crd.york.ac.uk/prospero/display_record.php?ID=CRD42018110729

23 Hutton B, Salanti G, Caldwell DM, Chaimani A, Schmid CH, Cameron $C$, et al. The PRISMA extension statement for reporting of systematic reviews incorporating network meta-analyses of health care interventions: checklist and explanations. Ann Intern Med. 2015;162(11):777-784. Doi: 10.7326/M14-2385

24 Higgins JP, Altman DG, Sterne JA. Assessing risk of bias in included studies. In: Higgins JP, Green S, eds. Cochrane handbook for systematic reviews of interventions version 5.1.0 [Internet]. London: The Cochrane Collaboration; 2011 [cited 2019 Dec 12]. Available from: https://training.cochrane.org/handbook/archive/v5.1/

25 Manager R.(RevMan) [Computer program]. Version 5.3. Copenhagen: The Nordic Cochrane Centre/The Cochrane Collaboration; 2014

26 Guyatt G, Oxman AD, Akl EA, Kunz R, Vist G, Brozek J, et al. GRADE guidelines: 1. Introduction-GRADE evidence profiles and summary of findings tables. J Clin Epidemiol. 2011;64(04):383-394. Doi: $10.1016 /$ j.jclinepi.2010.04.026

\section{Appendix 1}

\#1 "Diabetes, Gestational"[Mesh] OR (Diabetes, PregnancyInduced) OR (Diabetes, Pregnancy Induced) OR (PregnancyInduced Diabetes) OR (Gestational Diabetes) OR (Diabetes Mellitus, Gestational) OR (Gestational Diabetes Mellitus) OR (GDM) \#2 "Pregnancy in Diabetics"[Mesh] OR Pregnancy in Diabetic OR Pregnancy in Diabetes OR Pregnancy in Diabete \#3 "Vitamin D"[Mesh] OR (D04.808.812.768) OR (D014807) OR (1406-16-2) OR (Vitamin D3) OR (25(OH)D) OR (25-hydroxyvitamin D)
27 Valizadeh M, Piri Z, Mohammadian F, Kamali K, Amir Moghadami HR. The impact of vitamin D supplementation on post-partum glucose tolerance and insulin resistance in gestational diabetes: a randomized controlled trial. Int J Endocrinol Metab. 2016;14(02): e34312. Doi: $10.5812 /$ ijem.34312

28 Yeow TP, Lim SL, Hor CP, Khir AS, Wan Mohamud WN, Pacini G. Impact of vitamin D replacement on markers of glucose metabolism and cardio-metabolic risk in women with former gestational diabetes-a double-blind, randomized controlled trial. PLoS One. 2015;10(06):e0129017. Doi: 10.1371/journal.pone.0129017

29 Hosseinzadeh-Shamsi-Anar M, Mozaffari-Khosravi H, Salami MA, Hadinedoushan H, Mozayan MR. The efficacy and safety of a high dose of vitamin $\mathrm{d}$ in mothers with gestational diabetes mellitus: a randomized controlled clinical trial. Iran J Med Sci. 2012;37(03): 159-165

30 Mozaffari-Khosravi H, Hosseinzadeh-Shamsi-Anar M, Salami MA, Hadinedoushan H, Mozayan MR. Effects of a single post-partum injection of a high dose of vitamin D on glucose tolerance and insulin resistance in mothers with first-time gestational diabetes mellitus. Diabet Med. 2012;29(01):36-42. Doi: 10.1111/j.14645491.2011.03473.x

31 Pleskačová A, Bartáková V, Pácal L, Pácal L, Kuricová KBělobrádková. et al. Vitamin D status in women with gestational diabetes mellitus during pregnancy and postpartum. BioMed Res Int. 2015;2015:260624. Doi: 10.1155/2015/260624

\#4 "Cholecalciferol"[Mesh] OR (Calciol) OR ((3 beta,5Z,7E)9,10-Secocholesta-5,7,10(19)-trien-3-ol) OR (Vitamin D 3) OR (Vitamin D3) OR (Cholecalciferols) OR (D04.808.247.222.159) OR (D04.808.247.808.146) OR (D04.808.812.768.196) OR (D10.570.938.146) OR CD002762) OR (1C6V77QF41)

\#5 "Postpartum Period"[Mesh] OR Period, Postpartum OR Postpartum OR Postpartum Women OR Women, Postpartum OR Puerperium

(\#1 OR \#2) AND (\#3 OR \#4) AND \#5 